\title{
Cutaneous vasculitis and immune complexes in severe bronchiectasis
}

\author{
ANGELA M HILTON, PS HASLETON, A BRADLOW, BC LEAHY, KM COOPER, M \\ MOORE
}

From the Departments of Chest Medicine and Pathology, Wythenshawe Hospital; and the Department of Immunology, Paterson Laboratories, Christie Hospital and Holt Radium Institute, Manchester

\begin{abstract}
Four patients with severe bronchiectasis (chronic bronchial suppuration) are described who developed cutaneous lesions associated with exacerbations of their respiratory disease. The skin abnormalities consisted of purpuric lesions in three patients and an erythematous vasculitis in one. Circulating immune complexes were present in all patients and in three skin biopsy specimens showed deposition of $\mathrm{C} 3, \mathrm{IgG}$, and $\mathrm{IgA}$ in dermal blood vessels. Haemophilus influenzae had been isolated from the sputum of all four patients and in two patients was present at the time the cutaneous lesions appeared. It is suggested that local immune complex deposition was responsible for the skin lesions which occurred during acute exacerbations of bronchiectasis.
\end{abstract}

In recent years various immunological abnormalities have been reported in patients with chronic bronchial suppuration (severe bronchiectasis). These abnormalities have included an increased incidence of autoantibodies, raised immunoglobulin concentrations, and circulating immune complexes. ${ }^{1-3}$ In addition, many immunological diseases have been shown to be associated with severe bronchiectasisfor example, autoimmune thyroiditis, pernicious anaemia, rheumatoid arthritis, systemic lupus erythematosus, and ulcerative colitis. ${ }^{14-6}$ In common with patients with other chronic pulmonary conditions, those with bronchiectasis have a high incidence of circulating immune complexes; ${ }^{7}$ but there have been few reports of cutaneous lesions associated with this disease and in a review of 35 patients with cutaneous vasculitis ${ }^{8}$ only one had bronchiectasis.

We report four patients with chronic bronchial suppuration who developed skin lesions of varying type and distribution in association with exacerbations of their respiratory symptoms. All had circulating immune complexes and in three patients there was histological evidence to suggest that local immune complex deposition may have mediated the cutaneous lesions.

Address for reprints: Dr Angela $M$ Hilton, Chest Clinic, Wythenshawe Hospital, Manchester M23 9LT.

Accepted 14 October 1983

\section{Case histories}

Clinical details of the four patients are summarised in table 1 .

\section{PATIENT 1}

A 68 year old man had an 18 year history of cough with the production of large amounts of purulent sputum. The onset of symptoms was not related to a specific illness and his symptoms had become progressively worse over the last few years, with increasing breathlessness on minimal exertion and the production of $100-200 \mathrm{ml}$ of purulent sputum daily. He had been a lifelong non-smoker and there was no family history of pulmonary disease or autoimmune disorders. Serial chest radiographs over a 10 year period showed progressive changes consistent with bronchiectasis. On examination there was no finger clubbing but he had coarse crackles over both lower lobes, worse on the left side. In June 1980 he noticed for the first time a raised, red, itchy rash affecting the index fingers and thumbs of both hands symmetrically (fig 1 ). The skin lesions would occur immediately before a severe exacerbation of his respiratory symptoms and lasted four to seven days, gradually fading as his condition improved with antibiotic treatment and physiotherapy.

During the 18 months from June 1980 to December 1981 he had at least eight similar episodes in which skin lesions recurred, affecting the index fingers and thumbs of both hands symmetri- 
Table 1 Clinical details of the patients studied

\begin{tabular}{|c|c|c|c|c|c|}
\hline Patient No & Age (y) & Sex & $\begin{array}{l}\text { Duration (y) of respiratory } \\
\text { symptoms }\end{array}$ & Dermatological diagnosis & $\begin{array}{l}\text { Time }(y) \text { since onset of skin } \\
\text { lesions }\end{array}$ \\
\hline $\begin{array}{l}1 \\
2 \\
3 \\
4\end{array}$ & $\begin{array}{l}68 \\
57 \\
59 \\
67\end{array}$ & $\begin{array}{l}\mathbf{M} \\
\mathbf{M} \\
\mathbf{M} \\
\mathbf{F}\end{array}$ & $\begin{array}{l}18 \\
26 \\
38 \\
12\end{array}$ & $\begin{array}{l}\text { Vasculitis } \\
\text { Purpura } \\
\text { Henoch-Schönlein purpura } \\
\text { Vasculitic purpura }\end{array}$ & $\begin{array}{l}22^{1 / 2} \\
15 \\
8 \\
2\end{array}$ \\
\hline
\end{tabular}

Table 2 Immunoglobulins and autoantibodies in the four patients (normal values shown in parentheses)

\begin{tabular}{|c|c|c|c|c|c|c|}
\hline Patient No & $\begin{array}{l}\operatorname{IgA} \\
(0.9-3.3 \mathrm{~g} / l)^{*}\end{array}$ & $\lg _{(7-15 g / l)^{*}}$ & $\begin{array}{l}\operatorname{lgM} \\
(0.55-2 \cdot 8 \mathrm{~g} / l)^{*}\end{array}$ & $\begin{array}{l}\text { Rhematoid } \\
\text { factor/SCAT }\end{array}$ & $\begin{array}{l}\text { Antinuclear } \\
\text { factor }\end{array}$ & $\begin{array}{l}\text { Smooth muscle } \\
\text { antibody }\end{array}$ \\
\hline $\begin{array}{l}1 \\
2 \\
3\end{array}$ & $\begin{array}{l}12 \cdot 5 \\
6 \cdot 7 \\
19\end{array}$ & $\begin{array}{l}11 \cdot 0 \\
13 \cdot 4 \\
27 \cdot 7\end{array}$ & $\begin{array}{l}0 \cdot 25 \\
0 \cdot 5 \\
0.5\end{array}$ & $\begin{array}{l}- \\
- \\
-\end{array}$ & $\begin{array}{l}- \\
- \\
+\end{array}$ & $\begin{array}{l}- \\
- \\
-\end{array}$ \\
\hline 4 & $0 \cdot 84$ & 19.4 & 0.7 & $\begin{array}{l}+ \\
(1 / 320) \\
\text { SCAT } 1 / 1024\end{array}$ & $(1 / 80)$ & + \\
\hline
\end{tabular}

* Values in italic in the columns are above the normal range.

+ indicates a positive and - a negative result.

SCAT-sheep cell agglutination test.

cally. On each occasion they were associated with or immediately preceded an acute exacerbation. With control of the respiratory symptoms the skin lesions faded and healed by exfoliation over a period of up to a week. In December 1981, because of repeated severe exacerbations and frequent hospital admissions during the preceding 18 months, he was started on long term antibiotic treatment with cotrimoxazole $480 \mathrm{mg}$ twice daily. Since that time his condition has been stable, with no severe acute exacerbations, hospital admissions, or recurrence of skin lesions.

Repeated sputum cultures over several years have frequently been sterile; but on two earlier occasions Pseudomonas aeruginosa organisms were isolated from his sputum, and during the period when he was

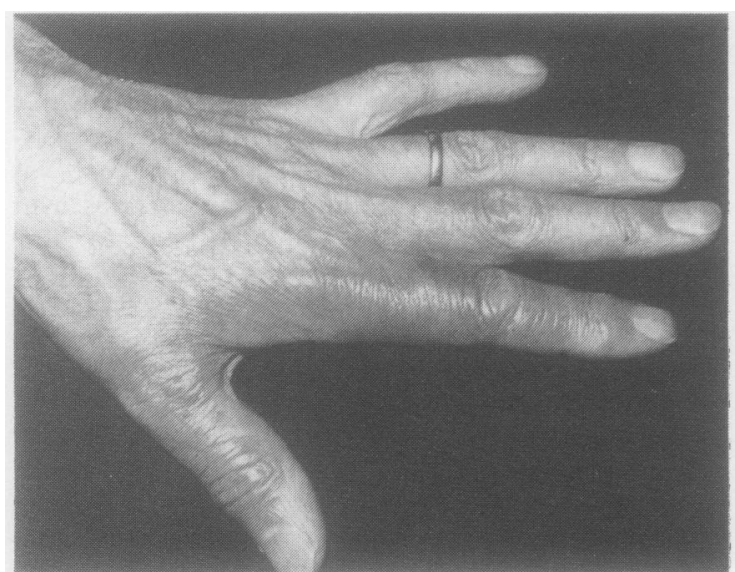

Fig 1 Left hand of patient 1 showing erythematous rash on the thumb and index finger. having recurrent episodes of vasculitis in July 1980 and September 1981 Haemophilus influenzae was grown.

Routine haematological and biochemical investigations and urine examination gave normal results. The serum immunoglobulin concentrations are listed in table 2. These were normal apart from a raised $\operatorname{IgA}$ concentration. The results of tests for autoantibodies were negative, as was the response to the aspergillus precipitin test. The results of complement studies included: $\mathrm{CH}_{50} 128 \%$ (normal), $\mathrm{C} 3$ $2 \cdot 22 \mathrm{~g} / \mathrm{l}$ (normal $0 \cdot 8-2 \cdot 8 \mathrm{~g} / \mathrm{l}$ ), and $\mathrm{C} 4$ normal.

\section{PATIENT 2}

A 57 year old man had a 25 year history of persistent cough productive of purulent sputum. There was no obvious precipitating illness and progressive changes of bronchiectasis had developed during 25 years. He was a non-smoker and there was no associated autoimmune disease or relevant family history. He produced about $100 \mathrm{ml}$ of purulent sputum daily. Fifteen years earlier he had developed purpura affecting both legs below the knees and both forearms. The purpuric lesions were most noticeable on his legs and were associated with pain in ankles and knees. At that time the results of coagulation studies were normal. Eight years ago a further episode of purpura occurred, associated this time with increasing dyspnoea, cough, and increased sputum production; for the first time he was noted to have cor pulmonale and hypercapnia. Further exacerbations of his chest condition requiring hospital admission occurred seven, six, and two years ago, but on these occasions no rash was noted. On his most recent admission in December 1982 for a 
severe exacerbation of bronchiectasis and cor pulmonale he had central cyanosis, finger clubbing and coarse crackles over both lower lobes; and small $(<0.5 \mathrm{~cm}$ diameter) round purpuric lesions were noted on both shins and forearms. The rash faded but did not entirely disappear with improvement in his symptoms after physiotherapy and antibiotic treatment. His chest radiograph showed extensive bilateral cystic bronchiectasis. The serum globulin concentration was raised at $41 \mathrm{~g} / \mathrm{l}$, with a raised $\operatorname{IgA}$ level (table 2). Platelets, the results of coagulation studies and the Hess test, and bleeding and clotting times were normal. The haemoglobulin concentration was $18.4 \mathrm{~g} / \mathrm{dl}$ with a packed cell volume of 0.61 . Sputum culture in 1968 had shown Haemophilus infuenzae but all subsequent sputum specimens were bacteriologically sterile. Complement studies gave normal results.

\section{PATIENT 3}

A 59 year old man presented in 1975 with a history of two episodes of pneumonia in his late teens. Since then he had regularly produced purulent sputum and at the age of 21 bronchiectasis had been diagnosed after a bronchogram. His condition remained stable, with regular sputum production and symptoms of mild airflow obstruction, until 1974. Over the subsequent nine years he had gradually deteriorated, with an increased volume and purulence of sputum and increasing dyspnoea.

On examination he had finger clubbing, central cyanosis, and coarse crackles at both lung bases. His chest radiograph showed evidence of cystic bronchiectasis predominantly affecting the right middle and right lower lobes. He had been a cigarette smoker until 1975.

In July 1976 he had had an episode of severe central abdominal pain and a purpuric rash over the buttocks, lower abdomen, and lower limbs. This was associated with an exacerbation of bronchiectasis and $H$ infuenzae had been cultured in the sputum. His haemoglobin concentration was $18 \mathrm{~g} / \mathrm{dl}$. The results of coagulation studies, bleeding time, platelets, and the response to the Hess test were normal. Gastroscopy showed purpuric lesions in the pyloric canal and duodenum, findings suggestive of Henoch-Schönlein purpura. Bouts of colicky pain persisted for several weeks and urine examination showed mild proteinuria but no evidence of red cells. From 1976 to 1979 his regular sputum production continued but there was no recurrence of the rash. In July 1979 further purpuric lesions were noted over his lower limbs, associated with an exacerbation of bronchiectasis. As the pulmonary symptoms improved with antibiotic treatment the rash disappeared. In January 1980 he was admitted with cor pulmonale associated with a purpuric rash over both lower limbs. When he had been treated with diuretics and oxygen and improved the rash faded. $H$ influenzae was again isolated from his sputum. Immunological investigations at this time showed a polyclonal increase in immunoglobulins; the response to the antinuclear factor test was weakly positive (table 2). The results of complement studies were within normal limits but he had elevated $\mathrm{C} 1 \mathrm{q}$ binding levels, suggesting the presence of circulating immune complexes (table 3 ).

\section{PATIENT 4}

This 65 year old woman had been attending the outpatient department for 10 years with gradually increasing dyspnoea on exertion and a cough productive of increasing amounts of purulent sputum. She had a history of cough and sputum production dating from a childhood chest infection. She was a lifelong non-smoker. Her chest radiograph showed ring shadows with areas of collapse and fibrosis throughout both lung fields, particularly in the upper zones, and the appearances were consistent with bronchiectasis. Six months before hospital admission in 1978 she had had two episodes of transient symmetrical polyarthralgia affecting the ankles, knees, hands, and wrists. No inflammatory synovitis was present but the result of the rheumatoid factor (latex) test was positive at $1 / 320$. The antinuclear antibody test gave a negative result. A few weeks later she developed a painless rash on both legs, which lasted several weeks and was associated with increased dyspnoea and increased sputum production. There had been no new antibiotic or other drug treatment immediately before the development of the rash.

On examination she had finger clubbing, splinter haemorrhages, and nail fold infarcts. There was an extensive symmetrical vasculitic rash consisting of raised purpura and ulcers covering both legs and feet. Her chest was hyperinflated with coarse crackles at both lung bases. Investigation showed an erythrocyte sedimentation rate of $82 \mathrm{~mm}$ in one hour; urine sterile on culture; and renal function, including blood urea, serum creatinine, and creatinine clearance, normal. Immunological investigations showed a raised IgG concentration, positive responses to the sheep cell agglutination test (SCAT) and latex test (table 2), a raised plasma C4 level, and considerably increased plasma C1q binding activity $(75 \%)$ (table 3 ). Numerous blood cultures were sterile, and sputum culture isolated Haemophilus influenzae. The patient was treated with high doses of prednisolone $(80 \mathrm{mg}$ daily) and amoxycillin ( $500 \mathrm{mg}$ four times a day), with gradual 
Table 3 Circulating immune complex assays in the four patients (normal ranges shown in parentheses)

\begin{tabular}{|c|c|c|c|}
\hline Patient No & Clq binding activity & PEG/SRID assay $\ddagger$ & \\
\hline 1 & $24.2 \%(<4.5 \%)^{*}$ & $\begin{array}{l}\text { IgG precipitate } 142 \mathrm{mg} / \mathrm{l}(<90) \\
\text { IgA precipitate } 49 \mathrm{mg} /(<20) \\
\text { IgM precipitate } 19 \mathrm{mg} / \mathrm{l}(<40) \\
\text { C1q precipitate } 116 \mathrm{mg} / \mathrm{l}(<60)\end{array}$ & $\begin{array}{l}+ \\
+ \\
+\end{array}$ \\
\hline 2 & 28 units $(<20)+$ & $\begin{array}{l}\text { IgG precipitate } 52 \mathrm{mg} / \mathrm{l} \\
\text { IgA precipitate } 14 \mathrm{mg} / \mathrm{l} \\
\text { IgM precipitate }<10 \mathrm{mg} / \mathrm{l}\end{array}$ & $\begin{array}{l}- \\
- \\
-\end{array}$ \\
\hline 3 & 57 units $(<20) \dagger$ & $\begin{array}{l}\text { IgG precipitate } 92 \mathrm{mg} / \mathrm{l} \\
\text { IgA precipitate } 24 \mathrm{mg} / \mathrm{l} \\
\text { IgM precipitate } 28 \mathrm{mg} / \mathrm{l} \\
\text { C1q precipitate } 98 \mathrm{mg} / \mathrm{l}\end{array}$ & $\begin{array}{l}+ \\
+ \\
+\end{array}$ \\
\hline 4 & $75 \%(<4.5 \%))^{*}$ & ND & \\
\hline
\end{tabular}

* Soluble phase $\mathrm{C1} \mathrm{q}$ binding assay.

† Solid phase C1q binding assay.

¥ Values in italic are above the normal range.

PEG—polyethylene glycol; SRID—-single radial immunodiffusion; ND—not done.

improvement in her chest condition and progressive resolution of the cutaneous vasculitis over six weeks.

\section{Methods}

MEASUREMENT OF CIRCULATING IMMUNE COMPLEXES

Clq binding assay (soluble phase): patients 1 and 4 C1q was prepared according to the method of Volanakis and Stroud ${ }^{9}$ and the $\mathrm{C} 1 \mathrm{q}$ binding assay was carried out as described by Zubler et al.$^{10}$ The results were expressed as the percentage of precipitated radioactivity, the upper limit of normal being $4.5 \%$.

Clq binding assay (solid phase): patients 2 and 3 The C1q binding assay was performed as described by Hay et al, ${ }^{11}$ and the results were expressed on a scale with a maximum of 100 units, the upper limit of normal being 20 units.

Polyethylene glycol (PEG) precipitation and single radial immunodiffusion (SRID): patients 1,2 and 3 The Mercia-Brocades CIC Kit (M 202) was used.

\section{HISTOPATHOLOGY}

Skin biopsy specimens were obtained from patients 1,2 , and 4 . $5 \mu \mathrm{m}$ sections were stained with haematoxylin and eosin, elastic van Gieson, and Martins scarlet blue (MSB) for fibrin. The sections for immunoglobulin and $\mathrm{C} 3$ determination were treated as follows. $5 \mu \mathrm{m}$ sections were deparaffinised in xylol and taken to alcohol; endogenous peroxidase was inhibited by treatment with $0.5 \% \quad \mathrm{H}_{2} \mathrm{O}_{2}$ in methanol for 10 minutes. The slides were washed well in tap water and then placed in distilled water at $37^{\circ} \mathrm{C}$ for 10 minutes. The sections were then treated with $0.1 \%$ trypsin and $0.1 \% \mathrm{CaCl}_{2}$ at $\mathrm{pH} 7.8$ for 15 minutes and washed with tris buffered saline (TBS) for 10 minutes on two occasions. The slides were then exposed to rabbit antihuman IgA, IgG, IgM, fibrinogen, and $\mathrm{C} 3$ at dilutions of $1 / 800$ (except for fibrinogen, which was at a dilution of $1 / 400$ ). The slides were washed in TBS on three occasions for 10 minutes each. Swine antirabbit IgG at a dilution of $1 / 400$ was added to the appropriate slides. The sections were washed again with TBS for three periods of 10 minutes. PAP (peroxidase-rabbit antiperoxidase) in a dilution of $1 / 500$ was added for 30 minutes. The slides were washed again in TBS and the horseradish peroxidase was visualised by using diamino benzidine and $\mathrm{H}_{2} \mathrm{O}_{2}$ for 10 minutes. The sections were then washed in TBS and in running tap water for five minutes. The sections were counterstained with haematoxylin, washed for two to three minutes, differentiated in $1 \%$ acid alcohol, "blued" by washing in Scott's tap water substitute for at least 10 minutes, dehydrated, cleared, and mounted. Negative controls were obtained by substituting TBS for the primary positive antiserum and positive controls were human tonsillar tissue; for $\mathrm{C} 3$ immunofluorescence material from a case of membranoproliferative glomerulonephritis was used.

\section{Results}

CIRCULATING IMMUNE COMPLEX ASSAYS

Table 3 summarises the results of assays of circulating immune complexes in the four patients. All patients were found to have increased $\mathrm{C1q}$ binding activity consistent with the presence of complement fixing circulating immune complexes measured by either the soluble or the solid phase assay. In addition, two patients ( 1 and 3 ) were found to have $\mathrm{IgG}$, IgA, and C1q containing immune complexes by the PEG-SRID method.

Figure 2 shows sequential measurements of $\mathrm{C} 1 \mathrm{q}$ binding activity (soluble phase method) in patient 1 over a period of two and a half years. Moderately high levels of circulating immune complexes were present during this time when intermittent episodes 


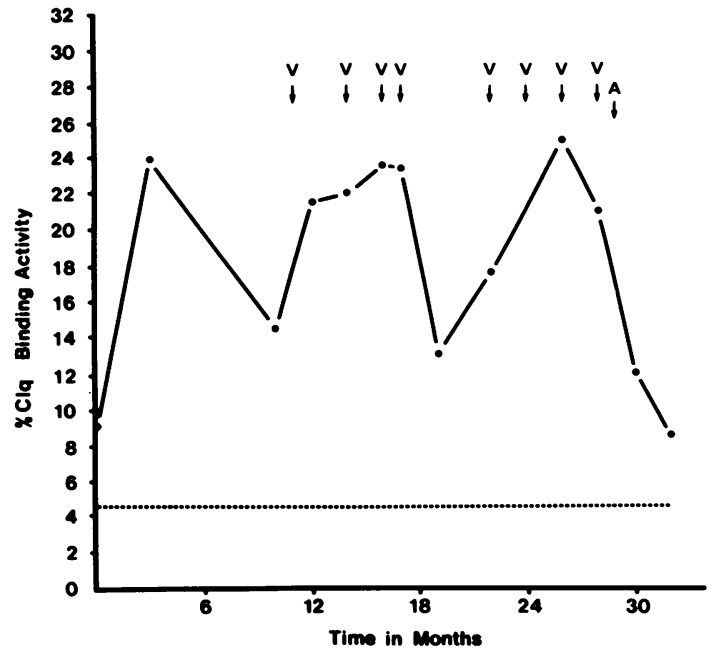

Fig 2 Sequential C1q binding activity in patient 1 measured for two and a half years and its relationship to the cutaneous lesions. $V$ indicates episodes of vasculitis and $A$ the start of long term antibiotic treatment.

of "vasculitis" occurred. Since he started long term antibiotic treatment there has been a fall in the immune complex levels and no further vasculitic episodes have developed.

\section{PATHOLOGY}

Patient 1 The epidermis was intact with no evidence of bullae or ulceration. In the dermis there were dilated blood vessels, two of which were surrounded by neutrophil polymorphs. The other vessels were cuffed by lymphocytes and histiocytes. No fibrinoid necrosis was present. There was dermal oedema and the endothelial cells were swollen. Immunoperoxidase staining showed IgA, IgG, IgM, $\mathrm{C} 3$, and fibrinogen in the vessel wall as well as in the dermis. The changes were strongly suggestive of anaphylactoid purpura.

Patient 2 The epidermis was intact and showed no ulceration or dysplasia. In the dermis there was oedema and around arterioles and capillaries there was an acute on chronic inflammatory reaction with lymphocytes, neutrophil polymorphs, and some eosinophils (fig $3 a$ ). No intravascular fibrin or fibrinoid necrosis was seen. Immunoperoxidase staining showed $\mathrm{C} 3$ on the luminal aspect of small vessels (fig $3 b$ ), IgG deposition occurring at the same site as well as in the vessel walls. IgG staining also occurred in the dermis and between epithelial cells, and IgA had the same distribution as IgG. IgM was seen in one blood vessel wall only. Fibrinogen was present in the dermis and in the lumen of some blood vessels. The histological features were those of anaphylactoid purpura.
Patient 4 The epidermis was intact and orderly with no evidence of bullae or ulceration. The superficial dermis was normal. In the deeper dermis the arterioles and capillaries were surrounded by acute inflammatory cells spreading out into the dermis with abscess formation in some areas. There was evidence of fibrinoid necrosis of the dermal vessels. Oedema and haemorrhage were also present in the dermis. Medium sized muscular arteries showed no evidence of fibrinoid necrosis or arteritis. On immunoperoxidase staining fibrinogen was identified in the affected blood vessel walls and in the dermis. IgA and IgM were seen in the lumen of affected and normal vessels and IgG was present in the walls of affected vessels. C3 was seen in some vessel walls but appeared mostly in those without fibrinoid necrosis and where the inflammation was least noticeabłe.

\section{Discussion}

Recent studies using three different assays have shown a very high incidence of circulating immune complexes in bronchiectasis. They were detected in about $80 \%$ of patients with bronchiectasis when all three assays were applied to each serum sample. Since the different methods detected complexes with differing properties in relation to their size, antibody content, ratio of antigen to antibody, and ability to fix complement, it was provisionally concluded that complexes in patients with bronchiectasis were heterogeneous in nature and that different types of complex could be present at any given time in individual patients.?

The four patients we have described with cutaneous lesions and bronchiectasis all had circulating immune complexes demonstrated by $\mathrm{C} 1 \mathrm{q}$ binding and therefore complement fixing. Patients 1 and 3 also had immune complexes detected by PEG precipitation. It is possible that such complement fixing complexes have a greater potential for deposition in tissues such as blood vessels, with resultant tissue damage, than complexes which are independent of complement. The fact that all patients had normal or raised complement levels would not exclude complement consumption by immune complexes. An increase in acute phase proteins during acute exacerbations could mask any depletion of $\mathrm{C} 3$ or $\mathrm{C} 4$ or both. The presence of $\mathrm{C} 3$ breakdown products would have provided suggestive evidence of complement consumption but the appropriate methods were not available when the patients were investigated.

The high incidence of circulating immune complexes in patients with chronic bronchial suppuration has previously led us to conclude that they 


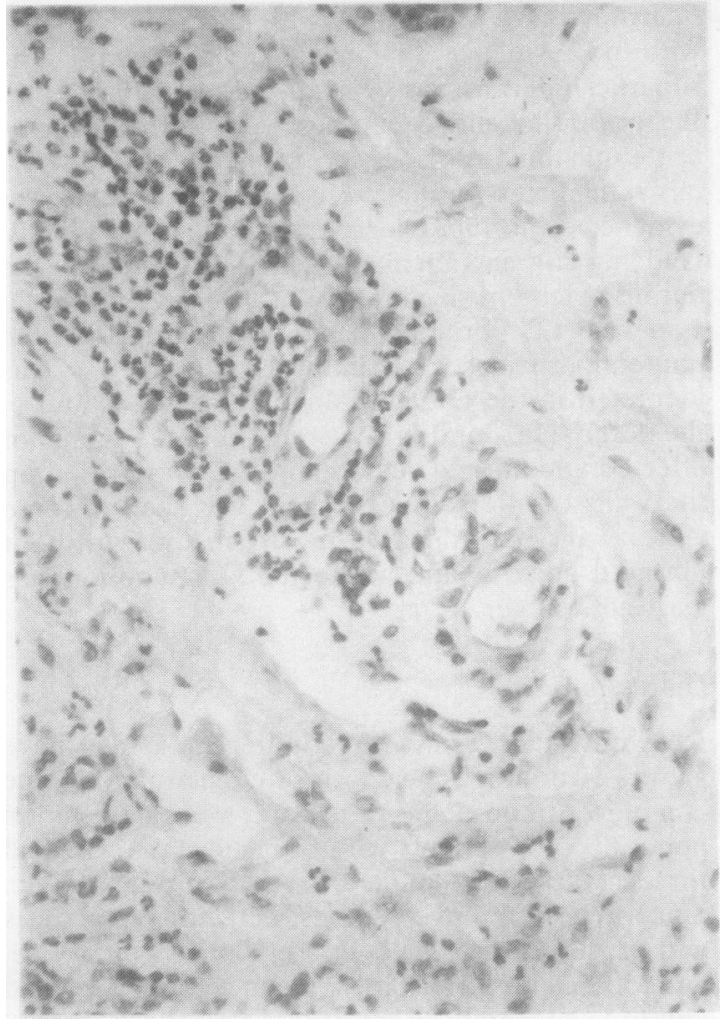

Fig 3 (a) Small blood vessels surrounded by acute and chronic inflammatory cells in the dermis of patient 2. (Haematoxylin and eosin, $\times 190$ ).

probably represent large amounts of antigen combined with antibody in the circulation resulting from persistent chronic antigenic stimulation. The antigen could be derived from an exogenous source such as bacterial products or from products of tissue destruction. $H$ influenzae had been isolated from the sputum of all four patients on at least one occasion, and in cases 1 and 3 was present in the sputum during exacerbations of respiratory symptoms associated with the cutaneous lesions. Possibly $H$ infuen$z a e$ or its products could form the antigenic component of the immune complexes in these patients, their persistence in the circulation resulting from a failure of normal clearance mechanisms.

There has been little previous evidence that such immune complexes are of pathological significance. In the four cases described here, however, we suggest that local immune complex deposition around blood vessels in the skin was responsible for the various cutaneous abnormalities which occurred in association with exacerbations of respiratory symptoms. The histological evidence of immunoglobulin and complement deposition in blood vessel walls,

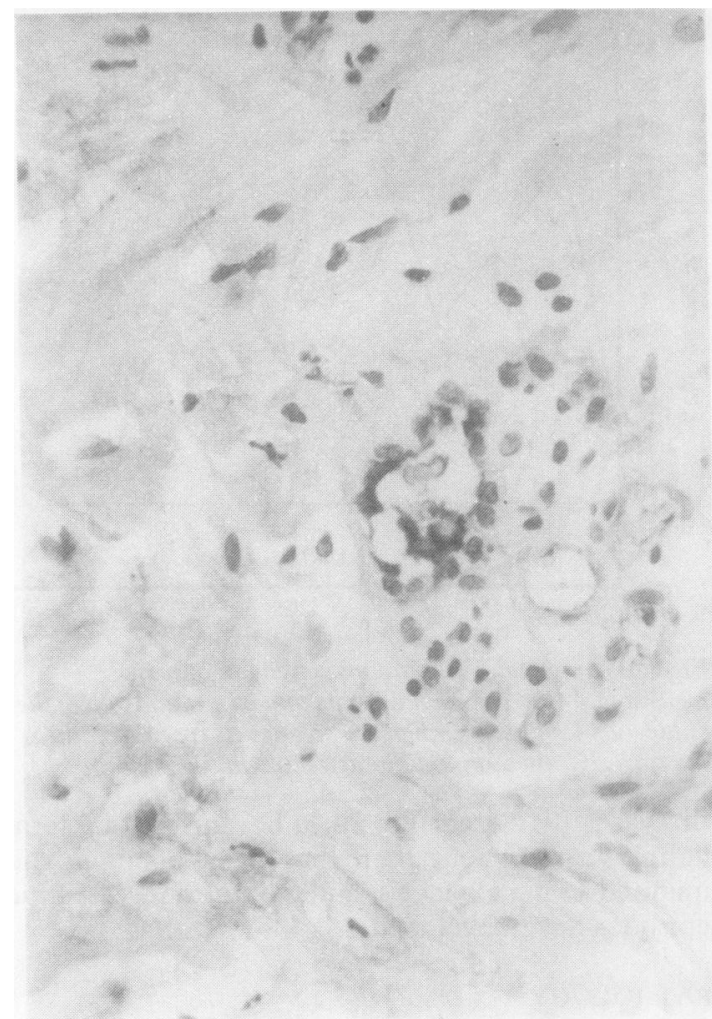

(b) Vessel in the dermis of patient 2 showing complement (C3) deposition on its luminal aspect. (Immunoperoxidase, $\times 190)$.

demonstrated in three patients by immunoperoxidase staining, would support this.

The histological changes were diagnostic of anaphylactoid purpura or allergic vasculitis in cases 2 and 4 and highly suggestive in case 1 . There was fibrinoid necrosis in case 4 and a well marked neutrophil polymorph reaction around both capillaries and arterioles in cases 1 and 4 . The sparing of muscular arteries excludes a diagnosis of polyarteritis nodosa. The pattern of immunoglobulin and C3 deposition has been noted previously by Schroeter et al, ${ }^{12}$ who showed deposits of IgG, C3, and in some cases IgM by direct immunofluoresence. Interestingly, in case 4 the complement was only seen in the vessel walls in the early stage of inflammation. Possibly once the complement dependent leucocytic infiltration had destroyed the vessel wall complement was lost. Occasionally this histological picture may be seen in systemic lupus erythematosus-with which bronchiectasis may be associated.'

Renal deposition of immune complexes, similar to those in the skin, may have mediated the Henoch- 
Schönlein purpura described in case 3 . This mechanism has been suggested as a cause of HenochSchönlein purpura in two patients with squamous cell carcinoma of the bronchus, where tumour antigen-IgA immune complexes were detected in renal tissue. ${ }^{13}$

Immune complexes could be important in other ways in patients with severe bronchiectasis. Local deposition of immune complexes in pulmonary tissue could perpetuate and increase tissue damage in the lungs. In cryptogenic fibrosing alveolitis immunological abnormalities similar to those described in bronchiectasis have been reportedthat is, raised immunoglobulin concentrations, ${ }^{14}$ increased autoantibodies, ${ }^{15}$ an increased incidence of autoimmune disease, ${ }^{16}$ and circulating immune complexes. ${ }^{1718}$ In addition, in fibrosing alveolitis immune complex deposition has been shown in alveolar walls and capillaries; ${ }^{1819}$ and there is experimental evidence that both the acute and the chronic changes of fibrosing alveolitis can be produced by immune complex deposition in lung tissue. ${ }^{2021}$

In malignant disease, where circulating immune complexes are frequently present, ${ }^{22}$ it has been suggested that such complexes may impair cell mediated immunity, thus favouring the spread of malignant disease. ${ }^{23}$ Similar impairment of normal host defences could be mediated by immune complexes in patients with severe bronchiectasis, contributing to their well established susceptibility to and increased frequency of recurrent infections, which must contribute to the further progression of the disease.

We thank Drs P Barnes, L Doyle, and TB Stretton for permission to report details of patients 2,3 , and 4 and also Professor J Ball for permission to study the sections from patient 4 and Dr RC Jennings for permission to study the sections from patient 1 . The solid phase C1q and PEG assays were performed by the regional immunology laboratory, St Mary's Hospital, Manchester.

\section{References}

${ }^{1}$ Hilton AM, Doyle L. Immunological abnormalities in bronchiectasis with chronic bronchial suppuration. $\mathrm{Br}$ J Dis Chest 1978;72:207-16.

${ }^{2}$ Hilton AM, Moore M, Howat JMT. Detection of circulating anticomplementary factors in chronic lung diseases. Clin Exp Immunol 1978;31:237-43.

${ }^{3}$ Cooper KM, Moore M, Hilton AM. C1q binding activity in the sera of patients with chronic lung diseases. Clin
Exp Immunol 1981;45:18-28.

${ }^{4}$ Walker WC. Pulmonary infections and rheumatoid arthritis. $Q J$ Med 1967;36:239-51.

${ }^{5}$ Mathieu JP, Stack BHR, Dick WC, Buchanan WW. Pulmonary infection and rheumatoid arthritis. $\mathrm{Br} J$ Dis Chest 1978;72:57-61.

- Butland RJA, Cole P, Citron KM, Turner-Warwick M. Chronic bronchial suppuration and inflammatory bowel disease. $Q J$ Med 1981;50:63-75.

' Cooper KM, Moore M. Heterogeneity of circulating immune complexes in chronic lung diseases. $J$ Clin Lab Immunol 1982;7:155-61.

${ }^{8}$ Cream JJ. Clinical and immunological aspects of cutaneous vasculitis. $Q J$ Med 1976;45:255-76.

- Volanakis JE, Stroud RM. Rabbit C1q: purification, functional and structional studies. J Immunol Meth 1972;2:25-34.

${ }^{10}$ Zubler RH, Lange G, Lambert PH, Miescher PA. Detection of immune complexes in unheated sera by a modified $125 \mathrm{I}-\mathrm{C} 1 \mathrm{q}$ binding test. J Immunol 1976;116:232-5.

" Hay FC, Nineham LJ, Roitt IM. Routine assay for the detection of immune complexes of known immunoglobulin class using solid phase C1q. Clin Exp Immunol 1976;24:396-400.

12 Schroeter AL, Copeman PWM, Jordan RE, Sams WM, Winkelmann RK. Immunofluorescence of cutaneous vasculitis associated with systemic disease. Arch Dermatol 1971;104:254-9.

${ }^{13}$ Cairns SA, Mallick NP, Lawler W, Williams G. Squamous cell carcinoma of bronchus presenting with Henoch-Schönlein purpura. Br Med J 1978;ii:474-5.

${ }^{14}$ Hobbs JR, Turner-Warwick M. Assay of circulating immuno-globulins in patients with fibrosing alveolitis. Clin Exp Immunol 1967;2:645-52.

15 Turner-Warwick M, Haslam P. Antibodies in some chronic fibrosing lung diseases. I Non-organ specific autoantibodies. Clin Allergy 1971;1:83-95.

${ }^{16}$ Turner-Warwick M. Immunology of the respiratory tract. Br J Hosp Med 1973;9:19-26.

${ }^{17}$ Haslam PL, Thompson B, Mohammed I. et al. Circulating immune complexes in patients with cryptogenic fibrosing alveolitis. Clin Exp Immunol 1979;37:38190.

${ }^{18}$ Dreisin RB, Scharz MI, Theofilopoulos AN, Stanford RE. Circulating immune complexes in the idiopathic interstitial pneumonias. $N$ Engl $J$ Med 1978;298:353-7.

${ }^{19}$ Turner-Warwick M, Haslam P, Weeks J. Antibodies in some chronic fibrosing lung diseases. II Immunofluorescent studies. Clin Allergy 1971;1:209-19.

${ }^{20}$ Scherzer $\mathrm{H}$, Ward PA. Lung and dermal vascular injury produced by preformed immune complexes. Am Rev Respir Dis 1978;117:551-7.

${ }^{2}$ Brentjens JR, O'Connell DW, Pawlowski IB, Hsu KC, Andres GA. Experimental immune complex disease of the lung. J Exp Med 1974;140:105-25.

22 Samayoa EA, McDuffie FC, Nelson AM, Go VLW, Luthra HS, Brumfield HW. Immunoglobulin complexes in sera of patients with malignancy. Int J Cancer 1977;19:12-7.

${ }^{23}$ Theofilopoulos AN. Immune complexes in cancer. $N$ Engl J Med 1982;307:1208-9. 